\title{
JUDICIALIZAÇÃO DA EDUCAÇÃO: INTERFERÊNCIA JUDICIAL APROFUNDA DESIGUALDADE NO ACESSO EM CRECHE POR QUEM MAIS PRECISA DELE
}

\author{
José Claudinei Lombardi ${ }^{1}$
}

\section{RESUMO}

O artigo trata da escalada de judicialização da educação pública municipal, voltando-se à defesa de uma lei que estabelece critérios para a ocupação de vagas em creche - o Programa "Creche com Fila Única". Com base na Constituição Federal (CF), no Estatuto da Criança e do Adolescente (ECA) e da Lei de Diretrizes e Bases da Educação (LDB), desde o ponto de vista do gestor da educação, incursiona sobre as bases e fundamentos legais da educação infantil. Há um arraigado senso comum de interpretação jurídica que pressupõe que se deva tratar como iguais crianças que estão efetivamente em situação de desigualmente. Esses fazem a defesa da igualdade perante a lei, como a única ou a melhor forma de garantir direitos a todos indistintamente. Entretanto, como a sociedade capitalista está longe da pressuposta igualdade econômica, social e política, é preciso garantir a igualdade para os que são socialmente desiguais. Contrapondo-se ao senso comum jurídico e à repetição da tese que trata a creche como direito objetivo, líquido e certo, fundada no reconhecimento liberal da igualdade de todos perante a lei, defende-se a tese de que também no que diz respeito ao acesso de vaga em creche, deve-se adotar o princípio de garantir igualdade para os que são socialmente desiguais, estabelecendo critérios para as vagas nas creches municipais públicas.

Palavras-chave: Educação Brasileira; educação infantil; creche; educação municipal; Limeira-SP

\section{JUDICIALIZATION EDUCATION: JUDICIAL INTERFERENCE DEEPENS DIFFERENCE IN ACCESS IN NURSERY BY THOSE WHO NEED IT MOST}

\begin{abstract}
The article deals with the escalating legalization of municipal public education, returning to the defense of a law that establishes criteria for the occupation of vacancies in nursery the Program "Creche com Fila Única". Based on the Federal Constitution (FC), the Statute of Children and Adolescents (ECA) and the Law of Guidelines and Bases of Education (LDB), from the point of view of the manager of education incursion on the bases and legal foundations of early childhood education. There is an ingrained sense of common legal interpretation presupposes that we should treat children as equals who are actually in a situation of unevenly. These are the defense of equality before the law as the only or the best way to guarantee rights to all without distinction. However, as the capitalist society is far from the assumed economic, social and political equality, we need to ensure equality for those who are socially unequal. Opposed to the common legal sense and the repetition of the thesis is that the daycare as objective law, clear and certain, founded in the liberal recognition of the equality of all before the law, defends the thesis that also with regard to access vacancy in daycare, one should adopt the principle of ensuring equality for those who are socially unequal, establishing criteria for vacancies in public daycare centers.

Keywords: Brazilian education; early childhood education; nursery; municipal education; Limeira-SP
\end{abstract}


O presente artigo resulta dos embates em torno do entendimento sobre a questão do acesso a vagas em creche, e que tem gerado verdadeira batalha judicial envolvendo as Secretarias Municipais de Educação, o Ministério Público e o Judiciário. A escalada de mandados de segurança, com a concessão de liminares determinando ao poder público a matrícula de crianças de zero a três anos em creches públicas ou privadas, a expensas dos recursos públicos destinados à educação obrigatória, vem sofrendo rápido crescimento: até 2012 ocorriam em quantidade reduzida, não passando de uma dezena; em 2013 foram 58 liminares concedidas, quantidade que em apenas um ano mais que duplicou, pois até a data de fechamento deste artigo (18 de novembro de 2014) foram 122 as determinações liminares por vaga em creche.

Nas colocações que seguem não estou me pronunciando, e nem devo, como jurista, mas simplesmente como um educador que possui formação no campo da Filosofia e das Ciências Sociais, com doutorado e livre-docência no campo da Filosofia e História da Educação, e que está na condição de Secretário Municipal de Educação, de $1^{\circ}$. de janeiro de 2013 até a presente data. Nessa condição, duas observações iniciais se fazem necessárias. A primeira é que, como gestor da educação municipal, sou considerado "autoridade coatora" pelo judiciário e, por isso, sujeito às penalidades previstas em lei e a multa, não restando alternativa que não seja o cumprimento de toda determinação judicial; apenas depois disso, é que a ação deve ser respondida e questionada no âmbito judicial adequado; um segundo aspecto é que, quantitativamente, a situação educacional em Limeira é relativamente tranquila e privilegiada, pois:

- $\quad$ No Ensino Fundamental, em 2014 está havendo o atendimento de 12.007 alunos da primeira etapa desse nível de ensino e que é assumida em âmbito municipal ( $1^{\mathrm{a}}$. a $5^{\mathrm{a}}$. Séries). Este nível ESTÁ UNIVERSALIZADO no município de Limeira-SP, pois todos os alunos dessa faixa de idade escolar estão devidamente matriculados. Universalizado o atendimento, busca-se ampliar o atendimento em tempo integral - hoje totalizando $10,8 \%$ dos alunos das séries iniciais do Ensino Fundamental.

- Na Educação Pré-Escolar (2a . etapa da Educação Infantil): em 2014 ocorre o atendimento de 5.866 alunos da educação pré-escolar (que é a $2^{\mathrm{a}}$ etapa da educação infantil, voltada ao atendimento de crianças entre 4 a 5 anos de idade); e esta etapa também ESTÁ UNIVERSALIZADDA neste ano (2014), situação prevista para acontecer em 2016 pela legislação nacional. Desse total, $2.087(35,6 \%)$ alunos são atendidos em tempo integral.

- No atendimento em CRECHE, 1 ${ }^{\text {a }}$. Etapa da Educação Infantil, e que legalmente deve atender crianças até os três anos, os dados quantitativos apresentam a seguinte situação: a) as unidades municipais atendem um total de 3.952 crianças, sendo $931(23,6 \%)$ em tempo parcial e $3.021(76,4 \%)$ em tempo integral; b) o atendimento pelo Programa Bolsa Creche é de 1.407 infantes em tempo integral; c) o total é de 5.359 alunos atendidos pelo Município (73,7 \% na rede municipal e 26,3 \% em instituições conveniadas); d) pelo sistema centralizado de cadastro em vagas (CiControl), estabelecido com o Programa "Creche com Fila Única", há atualmente um total de 1.422 inscritos aguardando vaga no município de Limeira; e) essa fila é substantivamente menor em relação ao período em que não havia o programa de fila única, quando em 27 de 
setembro de 2013 chegou-se a ter 3.346 inscritos (segue consulta em anexo).; f) a análise do banco de dados evidenciou que isso decorria da existência de múltiplas entradas de informações (pelas Unidades Escolares), resultando em muitas crianças terem cadastro múltiplo, distorcendo a efetiva demanda por vaga em creche no município.

Nos termos da legislação em vigor, o atendimento em creche, previsto na Constituição Federal de 1988 e na Lei de Diretrizes e Bases da Educação Nacional (Lei no. 9.394, de 20 de dezembro de 1996), é a primeira etapa da educação infantil e voltada ao atendimento de crianças até os três anos de idade (faixa de 0 a 3 anos de idade). A etapa seguinte é a Pré-escolar para crianças de quatro e cinco anos de idade.

$\mathrm{O}$ atendimento em CRECHE, por suas peculiaridades, é uma etapa particularmente especial no processo de formação humana, pois é dedicada ao atendimento de bebês e que, por isso, ainda necessitam dos cuidados maternos e da atenção formativa da FAMÍLIA; a etapa denominada de "pré-escola", e que mantém a denominação clássica que a entendia como um período imediatamente anterior ao escolar, mas que hoje, por força da própria LDB, é considerado como o inicio do processo de escolarização obrigatória para todas as crianças e que abrange toda a educação básica e que, por força da Emenda Constitucional $\mathrm{n}^{\circ}$ 59, de 11 de novembro de 2009, abrange a faixa etária dos 4 aos 17 anos de idade. Essa Emenda Constitucional deverá ser implementada, progressivamente, até 2016; essa EC somente foi regulamentada por meio da Lei $\mathrm{n}^{\circ}$ 12.796, de 4 de abril de 2013, alterando a LDB (Lei de Diretrizes e Bases da Educação Nacional).

Feitos esses esclarecimentos, e tendo anteriormente apresentado os dados quantitativos da educação municipal de Limeira, no que diz respeito ao atendimento em creche, é preciso reconhecer que há carência de vagas no município! Para o gestor, porém, o necessário planejamento da expansão de qualquer nível educacional exige o cotejamento dos dados educacionais com a dinâmica populacional para cada uma das faixas etárias atendidas por cada etapa da educação. Recorrendo-se à dinâmica populacional de Limeira, constata-se que está havendo crescimento negativo (em torno de $-18 \%$ ) da população de 0 a 3 anos e das faixas etárias seguintes. Essa situação exige, com base nos dados existentes, a projeção estimativa para o futuro, para que não se incorra na construção de "elefantes brancos" - ou de edificações de unidades escolares (ou de prédios públicos) que rapidamente perdem sentido e função, muitas vezes antes de estarem concluídos.

Em face de tal situação, qual o encaminhamento que a administração municipal deve dar à falta de vagas em creche? Vários caminhos são possíveis, mas a adoção do Planejamento Estratégico por toda a administração municipal de Limeira, fez com que, no âmbito da Secretaria Municipal da Educação, fossem adotados, simultaneamente, os seguintes encaminhamentos: 1) por um lado, ampliamos os estudos sobre o perfil das famílias que demandam por vaga e que resultaram no Programa "Creche com Fila Única"; 2) por outro lado, aprofundamos os estudos estatísticos da população, notadamente a comparação entre a dinâmica populacional e o comportamento da demanda por vagas, buscando assim estabelecer uma projeção mais segura das necessidades de construção de novas unidades de educação infantil. 
Observação necessária é que esses estudos também acabaram desvelando a ocorrência de duas situações impactantes: a) a ocupação de vagas em creche por crianças cujas famílias, rigorosamente, não precisam manter seus bebês fora da convivência familiar, mas que se eximiam, por motivos que não dizem respeito à educação, da responsabilidade dos cuidados com seus filhos; b) como já afirmado, o cadastro informatizado possibilitava múltiplas entradas das informações, tendo muitas crianças mais de uma vez cadastradas no sistema informatizado de controle das vagas.

A solução foi a adoção de medidas que, a um só tempo, levasse à construção de novos Centros Infantis (CIs), a centralização do sistema de controle das informações e o estabelecimento de critérios para a ocupação das vagas. Para administrar a situação existente, sem a tomada de medidas paliativas, como a redução de vagas em tempo integral e a ampliação do atendimento em tempo parcial, que, em 27 de dezembro de 2003, foi aprovada a Lei no. 5.206, e depois o decreto $n^{\circ} 32$, publicado na edição de 29 de janeiro de 2004, do Jornal Oficial do Município, que estabeleceu que o Programa "Creche com Fila Única". É preciso afirmar, para que não paire nenhuma dúvida, que em nenhum momento houve qualquer tipo de maquiavelismo ou manobra que levasse à exclusão de crianças da educação infantil; mas, face as evidentes distorções do sistema de controle de vagas, bem como a inexistência de vagas para todos, o que se pretendeu, simplesmente, foi centralizar o cadastro de demanda de vaga e estabelecer critérios para o preenchimento das vagas existentes.

Mesmo estando a Lei 5.206 sub judice, como educador considero que o Programa "Creche com Fila Única" é uma medida técnica necessária para a centralização da demanda em um cadastro único e para o estabelecimento de critérios que torne a igualdade dos que sofrem de desigualmente econômica e social um imperativo ético e jurídico (inciso III do Art. $3^{\circ}$. da CF). Também como educador penso que a solução para a falta de vagas é óbvia: a ampliação da oferta de vagas - que pode ser feita pela terceirização do atendimento (Bolsa Creche) ou pela construção de novas unidades escolares.

Como partilho do princípio que a educação é um direito do cidadão e um dever do Estado, e que recursos públicos da educação devem se destinar ao financiamento de uma educação pública, gratuita e de qualidade, voltei as ações da Secretaria Municipal da Educação para a busca dos recursos necessários à ampliação das vagas pela construção de novos Centros Infantis (CIs). Nessa direção, a Secretaria da Educação de Limeira obteve a aprovação, entre 2013 e inicio de 2014, de 10 (dez) novas Unidades Escolares, em bairros periféricos da cidade e com alta demanda de educação Infantil: 1 (uma) com a Secretaria da Educação do Governo do Estado de São Paulo e que será construída no bairro Morada das Acácias; outras 9 (nove) foram aprovadas pelo Governo Federal, através do Programa Pro-infância, do Ministério da Educação, sendo as cinco primeiras, integrando o Plano de Ações Articuladas (PAR) de 2012, completado e encaminhado em 2013, e serão localizadas nos seguintes bairros de Limeira: residencial Manoel Simão de Barros Levy, Jardim residencial Roseira, Geada, residencial Village e no residencial Belinha Ometto. As outras quatro foram aprovadas entre o segundo semestre de 2013 e neste inicio de 2014, e serão localizadas no Jardim Santina, Jardim Ibirapuera, Parque Hipólito e no Parque Residencial Alto dos Laranjais.

Cada uma dessas creches terá capacidade para atender 120 crianças em período integral ou 240 crianças em período parcial. A construção dessas creches quebra um jejum de vários anos da cidade de Limeira em receber investimentos governamentais para 
a educação (desde 2006) e, com essas construções, a previsão é que a demanda por vagas seja totalmente zerada. O planejamento para os próximos anos é para que não ocorra falta, mas também que não sobrem vagas, em nenhum dos níveis, a menos a curto e médio prazo, pois a ampliação do tempo integral é uma política educacional necessária, independentemente das opções políticas, partidárias e pedagógicas.

Com relação ao conteúdo do Programa "Creche com Fila Única", sobre o qual recai uma Ação de Inconstitucionalidade, ele é extremamente simples e expõe com objetividade os motivos e objetivos que normatiza:

- $\quad$ O Art. $1^{\circ}$. delimita a etapa educacional a que se refere - CRECHE - e a faixa etária definida pela Constituição Federal e Lei de Diretrizes e Bases da Educação Nacional para o atendimento - 0 a 3 anos de idade. Não se objetivou regulamentar a outra etapa da educação infantil (a pré-escola), pois, como exposto anteriormente, essa está com o atendimento universalizado no município, que já cumpriu com a obrigatoriedade de matricula escolar a partir dos quatro anos de idade.

- $\quad$ O Art. $2^{\circ}$. Trata da natureza do Programa e que é o estabelecimento de uma fila única para o acesso às vagas em creche, rompendo com o procedimento até então usual de cadastramento em cada Unidade Escolar da rede pública municipal. Trata-se simplesmente de adequar o banco de dados, centralizando todas as informações e que ficam disponíveis para a consulta de todos os interessados, bem como pelos públicos do executivo, legislativo e judiciário.

- O Art. $3^{\circ}$. Arrola os dados que, necessariamente, deverão constar do cadastro eletrônico.

- $\quad$ O Art. $4^{\circ}$. Objetivou regulamentar as condições e critérios para a efetivação das matrículas em CRECHE. Com esses critérios busca-se cumprir o estabelecido pelo Inciso XXV do Art. $7^{\circ}$. da $\mathrm{CF}$ que estabelece, como direito líquido e certo, dos trabalhadores urbanos e rurais, a assistência gratuita aos filhos e dependentes em creches e pré-escolas. ADEMAIS, atenta para a Lei de Diretrizes e Bases da Educação que, em seu Art. 29, estabelece que a educação infantil, primeira etapa da educação básica, deve possibilitar o desenvolvimento integral da criança, SENDO ESSA AÇÃO EDUCACIONAL COMPLEMENTAR A AÇÃO DA FAMÍLIA E DA COMUNIDADE.

Na elaboração da Lei no. 5.206 e que estabeleceu em Limeira o Programa de "Creche com Fila Única", buscamos atentar rigorosamente para a legislação em vigor, que estabelece a primazia de direitos dos trabalhadores para a assistência gratuita de seus filhos em creches e pré-escolas:

Art. $7^{\circ}$ São direitos dos trabalhadores urbanos e rurais, além de outros que visem à melhoria de sua condição social:

$[\ldots]$ 
XXV - assistência gratuita aos filhos e dependentes desde o nascimento até 5 (cinco) anos de idade em creches e pré-escolas; (Redação dada pela Emenda Constitucional nº 53, de 2006)

Isso não quer dizer que se desconhece o Art. 208, inciso IV, da Constituição Federal e que prescreve, como direito subjetivo, que o atendimento da educação infantil dos 4 aos 17 anos de idade - é dever do Estado:

Art. 208. O dever do Estado com a educação será efetivado mediante a garantia de:

I - ensino fundamental, obrigatório e gratuito, inclusive para os que a ele não tiveram acesso na idade própria;

II - progressiva extensão da obrigatoriedade e gratuidade ao ensino médio;

I - ensino fundamental, obrigatório e gratuito, assegurada, inclusive, sua oferta gratuita para todos os que a ele não tiveram acesso na idade própria; (Redação dada pela Emenda Constitucional n ${ }^{\circ}$ 14, de 1996)

I - educação básica obrigatória e gratuita dos 4 (quatro) aos 17 (dezessete) anos de idade, assegurada inclusive sua oferta gratuita para todos os que a ela não tiveram acesso na idade própria; (Redação dada pela Emenda Constitucional $\mathrm{n}^{\mathrm{o}} 59$, de 2009) (Vide Emenda Constitucional $n^{\circ} 59$, de 2009)

II - progressiva universalização do ensino médio gratuito; (Redação dada pela Emenda Constitucional $n^{\circ} 14$, de 1996)

III - atendimento educacional especializado aos portadores de deficiência, preferencialmente na rede regular de ensino;

IV - atendimento em creche e pré-escola às crianças de zero a seis anos de idade;

IV - educação infantil, em creche e pré-escola, às crianças até 5 (cinco) anos de idade; (Redação dada pela Emenda Constitucional $n^{\circ} 53$, de 2006)

$\cdots$

VII - atendimento ao educando, no ensino fundamental, através de programas suplementares de material didático-escolar, transporte, alimentação e assistência à saúde.

$\S 1^{\circ}-\mathrm{O}$ acesso ao ensino obrigatório e gratuito é direito público subjetivo.

$\S 2^{\circ}$ - O não-oferecimento do ensino obrigatório pelo Poder Público, ou sua oferta irregular, importa responsabilidade da autoridade competente.

$\S 3^{\circ}$ - Compete ao Poder Público recensear os educandos no ensino fundamental, fazer-lhes a chamada e zelar, junto aos pais ou responsáveis, pela frequência à escola.

Também não é desconhecido que o Estatuto da Criança e Adolescente - Lei no. 8.069, de 13 de julho de 1990 - que, por sua vez, também prescreve, de modo genérico, na mesma direção de garantir o direito à educação para todas as crianças e adolescentes: 
Art. 53. A criança e o adolescente têm direito à educação, visando ao pleno desenvolvimento de sua pessoa, preparo para o exercício da cidadania e qualificação para o trabalho, assegurando-se-lhes:

(...)

V - acesso à escola pública e gratuita próxima de sua residência.

Mas ao assegurar o direito à educação, enquanto direito subjetivo, deve-se atentar para os termos do art. 227 da Constituição Federal, que estabelece a corresponsabilidade da família, da sociedade e do Estado em assegurar à criança seus direitos:

Art. 227. É dever da família, da sociedade e do Estado assegurar à criança, ao adolescente e ao jovem, com absoluta prioridade, o direito à vida, à saúde, à alimentação, à educação, ao lazer, à profisssionalização, à cultura, à dignidade, ao respeito, à liberdade e à convivência familiar $\mathrm{e}$ comunitária, além de colocá-los a salvo de toda forma de negligência, discriminação, exploração, violência, crueldade e opressão. (Redação dada Pela Emenda Constitucional no 65, de 2010).

Não há dúvida que ao Estado cabe prover pública e gratuitamente o atendimento ao ensino fundamental como fica devidamente explicitado no $\S 1^{\circ}$, da alínea VII do Artigo 208 da CF, que coloca este como um direito público subjetivo - e que, portanto, lato sensu é um "direito do sujeito". Recentemente houve mudança quanto à obrigatoriedade da educação infantil. Inicialmente, atendendo disposto na Constituição Federal de 1988, em 26 de dezembro de 1996, foi editada a Lei no 9.394/96 - Lei de Diretrizes e Bases da Educação (LDB), houve regulamentação de vários aspectos e questões dos processos formativos e que se desenvolvem na vida familiar, na convivência humana, no trabalho, nas instituições de ensino e pesquisa, nos movimentos sociais e organizações da sociedade civil e nas manifestações culturais. A OBRIGATORIEDADE de educação infantil pública e gratuita ficou definida também nessa lei a partir dos 5 (cinco) anos de idade, MAS, o caráter público e OBRIGATÓRIO da educação infantil foi mudado por alterações da Lei de Diretrizes e Bases da Educação Nacional, através da LEI No 12.796, de 4 de abril de 2013, que entre outras mudanças, no Art. $4^{\circ}$. Inciso I, reduz a OBRIGATORIEDADE de matrícula em escolas de Educação Infantil para crianças a partir de 4 anos de idade. Hoje a base legal é que segue:

Art. $4^{\circ} \mathrm{O}$ dever do Estado com educação escolar pública será efetivado mediante a garantia de:

I - educação básica obrigatória e gratuita dos 4 (quatro) aos 17 (dezessete) anos de idade, organizada da seguinte forma: (Redação dada pela Lei no 12.796 , de 2013)

a) pré-escola; (Incluído pela Lei n ${ }^{\circ} 12.796$, de 2013)

b) ensino fundamental; (Incluído pela Lei $\mathrm{n}^{\circ}$ 12.796, de 2013)

c) ensino médio; (Incluído pela Lei n ${ }^{\circ} 12.796$, de 2013)

II - educação infantil gratuita às crianças de até 5 (cinco) anos de idade; (Redação dada pela Lei n ${ }^{\circ} 12.796$, de 2013)

$\S 2^{\circ}$ Em todas as esferas administrativas, o Poder Público assegurará em primeiro lugar o acesso ao ensino obrigatório, nos termos deste artigo, contemplando em seguida os demais níveis e 
modalidades de ensino, conforme as prioridades constitucionais e legais.

A legislação educacional, que é certamente complexa, não deixa dúvidas que a obrigatoriedade e gratuidade da educação escolar são para crianças, adolescentes e jovens entre os 04 (quatro) e os 17 (dezessete) anos de idade, sendo que a idade mínima limite deverá ser obrigatoriamente cumprida a partir de 2016. A obrigatoriedade engloba a educação pré-escolar, o ensino fundamental e o ensino médio.

Em que pesem essas diretrizes mais gerais da Carta Magna brasileira, atentamos para a regulamentação da educação pela Lei Ordinária Federal no 9.394/96 e que, deixando patente sua importância em estabelecer as bases, fundamentos e diretrizes para a educação nacional, recebeu a denominação de "Lei de Diretrizes Básicas da Educação" LDB), regulamentando a educação infantil nos seguintes termos:

Art. 29. A educação infantil, primeira etapa da educação básica, tem como finalidade o desenvolvimento integral da criança de até seis anos de idade, em seus aspectos físico, psicológico, intelectual e social, complementando a ação da família e da comunidade.

Art. 30 - A educação infantil será oferecida em:

I - creche ou entidades equivalentes, ou entidades equivalentes, para crianças de até três anos de idade;

II - pré-escolas, para as crianças de quatro a seis anos de idade.

Em que pese o volumoso e unânime entendimento jurisprudencial estabelecendo a obrigação do Poder Público em oferecer o atendimento educacional para crianças de zero a seis anos, no meu entendimento, essa prerrogativa jurídica impõe, ao Estado, pela alta significação social de que se reveste a educação infantil, a obrigação de criar condições objetivas e subjetivas que possibilitem, de maneira concreta, ação em favor das "crianças até 5 (cinco) anos de idade", viabilizando a elas o efetivo acesso e atendimento em creches e unidades de pré-escola.

Também entendo que toda criança deve ter seus direitos fundamentais garantidos, não podendo submeter-se a avaliações meramente discricionárias da Administração Pública, nem a subordinar-se a razões de puro pragmatismo governamental. E ainda, que cabe prioritariamente aos Municípios a atuação no ensino fundamental e na educação infantil $\left(\mathrm{CF}\right.$, art. $\left.211, \S 2^{\circ}\right)$ e que, por isso, as autoridades municipais não podem omitir-se ao que foi estabelecido pelo art. 208, IV, da CF da República, não devendo sua ação político-administrativa ser exercidas de modo a comprometer, com apoio em juízo de simples conveniência ou de mera oportunidade, a eficácia desse direito básico de índole social.

ENTRETANTO, não estamos tratando de assunto sem controvérsia e nem sempre o que é legal é o mais justo e possível do ponto de vista educacional. A jurisprudência anteriormente tratada pressupõe o princípio constitucional da igualdade entre todos os cidadãos. Mas filosoficamente sabemos que esse princípio liberal, diz respeito a uma igualdade pressuposta, ou perante a lei. Todos sabemos que há uma profunda desigualdade econômica, social e política entre os homens e que esta é notória e reconhecida pela unanimidade dos cientistas sociais e políticos, inclusive nas estatísticas internacionais e governamentais. É por isso que as leis máximas de todos os países 
civilizados e que adotam o princípio da igualdade perante a lei, igualmente estabelecem princípios para a defesa intransigente dos mais necessitados e fragilizados econômica, social e politicamente.

É também o que faz a Constituição brasileira que, reconhecendo a igualdade perante a lei, também estabelece, em seu Art. $3^{\circ}$, inciso III, como objetivo fundamental dos ententes federados da República a erradicação da pobreza e da marginalização e a redução das desigualdades sociais e regionais. A conceituação de "pobreza" não é consensual, pois se trata de um termo polissêmico; MAS certamente esta não pode ser apenas relacionada à falta de renda, mas também com a falta de alimentação, de moradia, de saneamento básico, de saúde, de educação, de acesso à informação, etc., pois são condicionantes que afetam a capacidade de autodeterminação dos cidadãos e ao pleno exercício dos direitos inerentes à cidadania. Como tratar como iguais, cidadãos que são socialmente diferentes? Cidadãos que reconhecidamente possuem condições diferenciadas de acesso aos serviços públicos e privados? Cidadãos que estão à margem da vida econômica e social?

$\mathrm{Na}$ maestria vocabular e discursiva de alguns juristas, entende-se que há efetivação do direito à educação quando se trata stricto sensu todas as crianças e jovens como iguais. Tenho, entretanto, me pronunciado aos Excelentíssimos Senhores representantes do judiciário que ao tratar como iguais crianças que estão efetivamente em situação de desigualmente, posto que a vulnerabilidade social é reconhecida por vários órgãos do Estado, ao contrário do que se pretende, estamos desrespeitando crianças, familiares e gestores nos mais diversos aspectos e, portanto, ignorando o Princípio da Dignidade da Pessoa Humana como norteador da efetivação dos direitos dos cidadãos brasileiros, já declarado no art. $1^{\circ}$, inciso III da Constituição Federal da Republica Federativa do Brasil.

Há certamente quem defenda ser a igualdade perante a lei, a única ou a melhor forma de garantir direitos a todos indistintamente. Mas, como não vivemos numa sociedade utópica na qual impere uma pressuposta igualdade econômica, social e política, um Estado-Ideal em que todos têm acesso aos bens e serviços de que necessita para uma existência plena, é preciso garantir a igualdade para os que são socialmente desiguais. Desde meu ponto de vista, expresso em vários trabalhos acadêmicos, isso até que ocorra uma profunda transformação econômica, social e política que coloque o exercício do poder sobre os desígnios societários efetivamente nas mãos da maioria da população. Isso corresponde, política e ideologicamente, a um projeto político que leve à demolição das bases da sociabilidade burguesa e à construção de uma sociedade justa e igualitária.

São esses os motivos que me levam, como educador, a defender a vigência de uma Lei como a que estabeleceu em Limeira - SP o Programa "Creche com Fila Única", na certeza de que sua implementação não objetiva a discriminação de uma única criança, mas que a curto-prazo ela será um simples instrumento para garantir o acesso de todas as crianças em creches municipais de Limeira, SP. 


\section{Referências}

BRASIL. Constituição da República Federativa do Brasil. Brasília. DF: Senado, 1988.

BRASIL. Estatuto da Criança e do Adolescente. Lei Federal n 8069, de 13 de julho de 1990.

BRASIL. Lei de Diretrizes Básicas da Educação" - LDB. Lei n. ${ }^{\circ}$ 9.394, de 20 de dezembro de 1996.

\section{Notas}

${ }^{1}$ Professor Livre-Docente do Departamento de Filosofia e História da Educação, da Faculdade de Educação
da Unicamp; Coordenador Executivo do HISTEDBR - Grupo de Estudos e Pesquisas "História, Sociedade
e Educação no Brasil”; Pesquisador bolsista do CNPq - Conselho Nacional de Desenvolvimento Científico
e Tecnológico; Secretário da Educação do Munípio de Limeira, SP.

Recebido: julho/14 Aprovado: agosto/14 